\title{
We Own This: A Class Patent System as Experiential Learning
}

\section{Dr. Joshua L. Hertz, Northeastern University}

Dr. Hertz earned a B.S. in Ceramic Engineering from Alfred University in 1999 and then a Ph.D. in Materials Science and Engineering from the Massachusetts Institute of Technology in 2006. Following this, he worked at the National Institute of Standards and Technology as a National Research Council postdoctoral fellow. He joined the Department of Mechanical Engineering at the University of Delaware as an Assistant Professor in September 2008, leading a lab that researched the effects of composition and nanostructure on ionic conduction and surface exchange in ceramic materials. In 2014, he moved to Northeastern University to focus on teaching and developing curriculum in the First Year Engineering program.

\section{Mr. Noah Daviero, Northeastern University}

Noah Daviero is an undergraduate student at Northeastern University pursuing his BS/MS in Mechanical Engineering and Mechatronics. He has interests in mechanical design and robotics, especially with regards to actuation and sensor feedback. He has completed a co-op at Waters Corporation, is currently on co-op at Corindus Vascular Robotics, and is a Teaching Assistant for Cornerstone of Engineering. 


\title{
We Own This: A Class Patent System as Experiential Learning
}

\begin{abstract}
This complete evidence-based practice paper presents a study on a new "class patent" system designed to increase first year engineering students' interest, understanding, and knowledge retention in the area of intellectual property. We describe here the conception, implementation, and analysis of this semester-long experiential learning activity, which was designed to make patent and trade secret concepts more grounded, engaging, and fun for students. We also include lessons learned during the implementation of the class patent system, in order to assist instructors who want to implement a similar system in their courses.

The class patent system was implemented in a required, 4 credit-hour, first-year engineering course at a medium-sized, private university. Course learning outcomes included topics in design and intellectual property, among a range of other foundational areas. Coursework included a major team-based, design-and-build project. This project had a slightly competitive aspect in that bonus points were awarded to the team that built the best project. Three years ago, one of the authors conceived and implemented a "class patent" system whereby teams could write and submit an application to patent a project idea. By patenting an idea, a team could hope to gain competitive advantage in achieving the best project.
\end{abstract}

As a pedagogical study, we sought to determine the effects of the class patent system on the class and learning outcomes. Specific research questions were: 1) What knowledge of patents and intellectual property protections have been retained from the class? 2) What role did the class patent system have on student learning outcomes related to the purpose and mechanics of patents? and 3) What role did the class patent system have on student experience in the class and, especially, the design project? A post-class student survey instrument was developed, and requests to complete the online survey were sent via email to all students who had taken the course while the class patent system was in place. This group covers the last two academic years, and the response rate to the survey was high at $53 \%$.

The lead finding of this work is that there is a positive correlation between a student's level of participation in the class patent system and the student's knowledge retention in patents. In addition, students reported very favorable opinions of the class patent system, with $92 \%$ of the students reporting that the class patent system led to "some" or "a lot" of learning about intellectual property.

\section{Introduction}

Instruction in intellectual property is common in engineering design curricula [1]-[5], because engineers typically must protect their creative design work with patents, trade secrets, and other forms of intellectual property. Though the ideas behind intellectual property are 
important and conceptually interesting, the details can be tedious, and the entire topic can end up being perceived by students as unexciting [6].

Experiential learning techniques cause a learner to have a direct sense experience with practice based on real-world tasks [7]. These techniques are closely associated with problembased learning, as both are learner-centered models that emphasize the autonomous actions of the learner in co-creating the educational experience. The role of the instructor in these techniques is, to a large degree, to design the experience, guide the learner, and provide feedback such that learning outcomes are met regardless of the choices made. Critics of experiential learning point out that it can de-emphasize the careful analysis and use of theory that an academic environment affords the student [8]. Nevertheless, many instructors find that experiential learning techniques are effective in increasing student motivation and emotional investment in course topics that might otherwise seem less relevant or exciting. Thus, we believe experiential learning may be especially relevant to the topic of intellectual property.

In [1], Gorman et al. describe an experiential learning activity about patents where student teams were given a set of materials and tasked to design and prototype an improvement to Bell's original patent on the telephone. A team deliverable was a patent document of their own, with an outside judge evaluating the basis of their claims. The authors reported that the instructors found the activity to be effective in teaching about both the frustrations and rewarding aspects of inventions and patents, and the vast majority of the students also found the activity to be rewarding. In [2], Garris and Garris describe a similar activity where student teams are given a real, US patent and told that they are either the rights holder, a licensee, or a competitor to the rights holder. They are then asked to design a new product in the market space of the patented ideas. They must design in a manner that corresponds to their role, either within the confines of the patent claims or as a non-infringing alternative.

The class patent system we created and describe here was modeled as much as possible after the US patent system while keeping foremost the objectives of achieving the course learning outcomes and maintaining a collegial and FERPA-compliant classroom environment. As described by Ambrose [9], class experiences that model real-world tasks are effective in creating a class environment that supports student motivation. As participation in the class patent system was voluntary for a student and did not directly affect their grade, this learning experience is considered a source of intrinsic motivation, in particular towards achieving learning goals as opposed to performance goals. The purposes of the class patent system were:

- to promote innovative project ideas;

- to encourage a diversity of project ideas from across the class;

- to motivate students to do significant creative work immediately when the project begins;

- to increase student interest in intellectual property; and

- to improve student learning in the purpose and mechanics of patents.

We note that the first three of these purposes closely mirror the main purpose of a real patent 
system, which is to encourage a society's rapid technological innovation [2]. Still, while it is desirable to encourage students to create new ideas rapidly, there was concern that the system could lead to student stress and hyper-competitiveness (which, it could be argued, would likewise mirror a real patent system).

\section{Description of the Class Patent System}

The class patent system was implemented in a required course for all first-year engineering majors. The focus of much of the work throughout the semester was a team design project, with many of the course's learning objectives implemented as specific project requirements. The project is very open-ended, with students given a general class of object to create (e.g., musical instrument, children's game) and a set of constraints (e.g., must stay under $\$ 100$ budget; must use an Arduino to sense, interpret, and respond to the user's actions, etc.) but otherwise given considerable flexibility in defining their team's end product, pursuant to multiple stages of instructor and peer review. Adding a competitive aspect, bonus points were awarded to a team's project grade if their final product was selected as the best.

Immediately after intellectual property concepts were covered in the class, students were notified that they could now gain competitive advantage over other project teams by patenting any project ideas they conceive. A document provided to the students described the logistics of the class patent system and detailed the envisioned educational and competitive benefits to the students for participating in this voluntary supplement to the class project work.

Teams could submit a class patent application for an overall project concept, a useful project component, an algorithm, or a design. The patent application had to include, among other items, a list of specific claims. If a class patent from one team was accepted by the patent examiner (the instructor), no other teams would be allowed to use in their project the concept(s) claimed. Unlike the real patent system, enforcement of patent claims was formally left to the instructor. Typically, enforcement involved a quick meeting with the infringing team to find a way to modify their idea so that it now fell into a useful gap in the other team's patent claims. Teams who subsequently felt that their patent was being infringed upon were likewise brought in for a quick discussion to see how the other team's idea fell into a gap in their claims. Having the class patent system thus generated very effective discussions about what patent claims mean, how they work, and why they are written as they are.

Class patent applications were submitted as a pdf file attached to an email to the instructor. A sample patent application is given in Appendix A. Each submitted patent application was soon published for all students to see on the course's Blackboard site. Applicants were then sent an email response that indicated whether the application had been accepted as is, accepted pending some small revisions, or rejected. If the application was rejected, the message indicated what about the claim(s) failed the test of being novel, non-obvious, and useful. Appeals to the decision were allowed, as were modified resubmissions. Where a revision was requested, it was typically to refine or remove one or more claims from a patent that had mostly acceptable 
claims. Most applications required at least one cycle of revisions to narrow or refine the patent claim(s), generating additional discussions with students about the nature of patent claims and the role of the patent examiner. Other common revision requests were to add a figure or additional text to clarify an idea, or to correct a mistake in who is listed as the inventor vs. the assignee. Specifically, the name(s) of the student(s) that actually conceived the idea(s) should be listed as the inventor(s), but their team name should be listed as the assignee. Once an application was accepted, a final patent document with valid, enforceable claims was published on the course website. It was also given an official class patent number, and an email was sent out to the entire class announcing the patent number and title.

In a real patent, the inventors are all listed by their full name and city of residence. As mentioned above, the class patent applications and granted patents were published on the course Blackboard site. It is a necessary component of a patent system that patent documents are published for all to see, but for student privacy reasons, it was decided that student names should not be included in the class patent documents made visible to all students. Instead, the instructor removed the inventor name(s) from the submitted applications and patents before posting. This procedure was explained to the class for the sake of clarity.

Being the patent examiner involves a certain time commitment. In our experience, running the class patent system for a total population of about 30 teams of 4 students each takes a few added hours per week. Without any change to the patent system, a teaching assistant could serve as an alternate patent examiner. The patent examination process did not involve detailed searching for similar ideas. Rather, any ideas that were not known or obvious to the instructor were considered sufficiently novel as to be worthy of a patent.

To reduce the workload of running the class patent system and to more closely model the real patent system, an "application fee" of sorts was implemented starting in year 2. Having some disincentive to the submission of a class patent application reduced the patent examiner's workload by ensuring that students submitted only their best ideas. Much like a company choosing whether to apply for a real patent, a team now must weigh the application "cost" relative to the competitive advantage gained from obtaining the patent and/or their ability to maintain their idea as a trade secret for the duration of the project. Since it would be clearly unethical to have students pay the instructor a monetary application fee, an alternative was needed. The projects for which this class patent system was created had a specified maximum budget; the class patent "application fee" was a $\$ 3$ reduction in the team's project budget for each application submitted. A revised submission of the same patent application did not require an additional application fee.

A future enhancement to the class patent system will be to create an official "open source registry." This enhancement will be done because occasionally a student team filed a patent application solely to ensure they could use their idea without getting blocked by another team filing a patent on the same idea. The team didn't really care if other teams also used this idea, as long as they were not prevented from doing so. While "defensive patenting" is a valid use of a 
patent system, an open source registry will be a more time and resource efficient option. The open source registry will allow students to publish their idea to the course Blackboard site without taking sole ownership rights but also without the "application fee." Open source registry documents will get published to the Blackboard site as received by the instructor (except in the case where a student's name or other unallowable content is included). Not only will this registry further the educational goals by adding open source principles to the intellectual property learning outcomes, but also it will reduce instructor workload in running the patent system by reducing the number of patent applications that must be read and responded to.

\section{Research Methods}

An online survey instrument was developed to study the effects of the class patent system. All study methods were preapproved by the University's Institutional Review Board. An email with a request to take a survey was sent to all students who completed the Spring 2017 or Spring 2018 term of the course and had the PI as their instructor. The email stated that the survey would take about 10-15 minutes to complete and would be about one aspect (but not which aspect) of their experience in the course. After the initial email, a reminder email was sent about 1 week later. Students who agreed to submit the survey were shown at the outset how the data collected would be used. They were asked at the beginning and end of the survey to confirm that they have read, understood, and agreed to the consent process for the use of their data.

The survey included four sections. The first section asked students to answer five questions that tested knowledge retention on patent topics. The topics were covered in class and were intended to be reinforced by the class patent exercise. As an example, students were asked to describe the difference between the inventor and the assignee listed on a patent. Students provided free-response answers to all five questions. The second section asked whether students remembered the class patent system. If they did not remember the class patent, the survey then asked for some demographic information and ended. Students who remembered the class patents were next asked questions to determine how much they participated in the system, such as whether they read any patents submitted by other teams or whether they wrote a patent application. After this, they were asked questions about their perceptions of the class patent system and its effect on learning and the class environment. Finally, they were then asked a set of demographic questions.

A number of the survey questions were encoded for quantitative analysis. Responses to each of the five knowledge retention questions were scored 0,1 , or 2 , giving each student respondent a final "knowledge retention score" out of 10. The degree to which each respondent participated in the class patent system was also quantified. A respondent who wrote or co-wrote a class patent application were given a full "participation level" of 2 . A respondent who did not participate in writing an application but remembered reading class patents written by other students was given a participation level of 1 . A respondent who did not remember reading or writing a class patent — or who could not remember the class patent system at all—was given a participation level of 0 . 


\section{Results and Analysis}

\section{Survey Respondents}

The response rate to the survey was $53 \%(\mathrm{n}=132)$. Sampling of the survey is representative of the class population with regards to both gender and Honors vs. non-Honors status. The response rate from women was $52 \%$, from men was $53 \%$, from Honors students was $55 \%$, and from non-Honors students was $50 \%$. A greater response rate was received from students who had more recently taken the class: $59 \%$ response from the 2018 class and $46 \%$ from the 2017 class.

Respondents generally reported a high GPA and a high degree of participation in the class patent system. A cross tabulation of the number of student respondents within each category of GPA and participation level is shown in Table 1. As can be seen, the respondents with GPAs in the middle ranges, values between 3.0 - 3.39, were fairly evenly split among participation levels 0,1 , and 2. Contrastingly, respondents in either the lower GPA ranges, between 2.6 - 2.99 or higher GPA ranges, between $3.4-4.0$, were much more likely to have participation levels of 1 or 2 . In understanding this phenomenon, it should be remembered that participating in the class patent system was not required and had no direct impact on a student's grade in the class.

Table 1. The number of survey respondents at each GPA range and "participation level" in the class patent system.

\begin{tabular}{|c|c|c|c|c|c|c|c|c|c|}
\hline & \multicolumn{8}{|c|}{ GPA } \\
\hline & & N/A & $\begin{array}{c}2.6- \\
2.79 \\
\end{array}$ & $\begin{array}{c}2.8- \\
2.99 \\
\end{array}$ & $\begin{array}{l}3.0- \\
3.19\end{array}$ & $\begin{array}{l}3.2- \\
3.39 \\
\end{array}$ & $\begin{array}{l}3.4- \\
3.59 \\
\end{array}$ & $\begin{array}{l}3.6- \\
3.79 \\
\end{array}$ & $\begin{array}{c}3.8- \\
4.0 \\
\end{array}$ \\
\hline \multirow{3}{*}{$\begin{array}{c}\text { Participation } \\
\text { Level }\end{array}$} & 0 & 2 & 0 & 0 & 4 & 4 & 4 & 8 & 10 \\
\hline & 1 & 0 & 0 & 2 & 4 & 4 & 7 & 11 & 14 \\
\hline & 2 & 1 & 1 & 1 & 5 & 5 & 11 & 14 & 20 \\
\hline
\end{tabular}

It is not known whether the respondents were representative of the class population with regards to GPA or participation level. Nothing in the invitation email requesting that students take the survey described the survey topic or in any way mentioned patents or intellectual property, so there is no reason to suspect a preferential survey response from students with a high participation level or a high self-perceived knowledge retention. Still, there may be an effect whereby students who felt unsure of their answers to the knowledge retention questions or who either did not remember the class patent system or had not participated in it may have preferentially chosen to start but not complete the survey. We were not able (either technically or according to the IRB approvals) to collect data from any such abandoned survey responses. Another potential source of non-representativeness that we cannot rule out is that students who more greatly valued their class experience may have preferentially responded to the survey request. 


\section{Knowledge Retention}

Students that responded to the survey had a generally high retention of knowledge about patents. Among all survey respondents, the median score was 9, and the mean score was 8.29 with a standard deviation of 1.54. The score had effectively zero dependence on gender $(\mathrm{p}=0.99)$ and a measurable but statistically insignificant dependence on Honors vs. non-Honors status $(\mathrm{p}=0.79)$. Students from the more recent class year had higher knowledge retention score on average, a score of 8.40 vs. a score of 8.15 for the previous class year, but the difference was again statistically insignificant $(\mathrm{p}=0.47)$. Knowledge retention had a non-monotonic dependence on GPA, as shown in figure 1. As can be seen, the lowest average knowledge retention scores came from the middle GPA ranges. It is unclear why this occurred. Based on the data shown in table 1, the two lowest GPA ranges had very small sample sizes. The students with the lowest reported GPAs also had a disproportionally high participation rate in the class patent system. As will be shown next, high participation in the class patent system is positively correlated with high knowledge retention. ANOVA shows no statistically significant difference in knowledge retention based on GPA $(p=0.48)$.

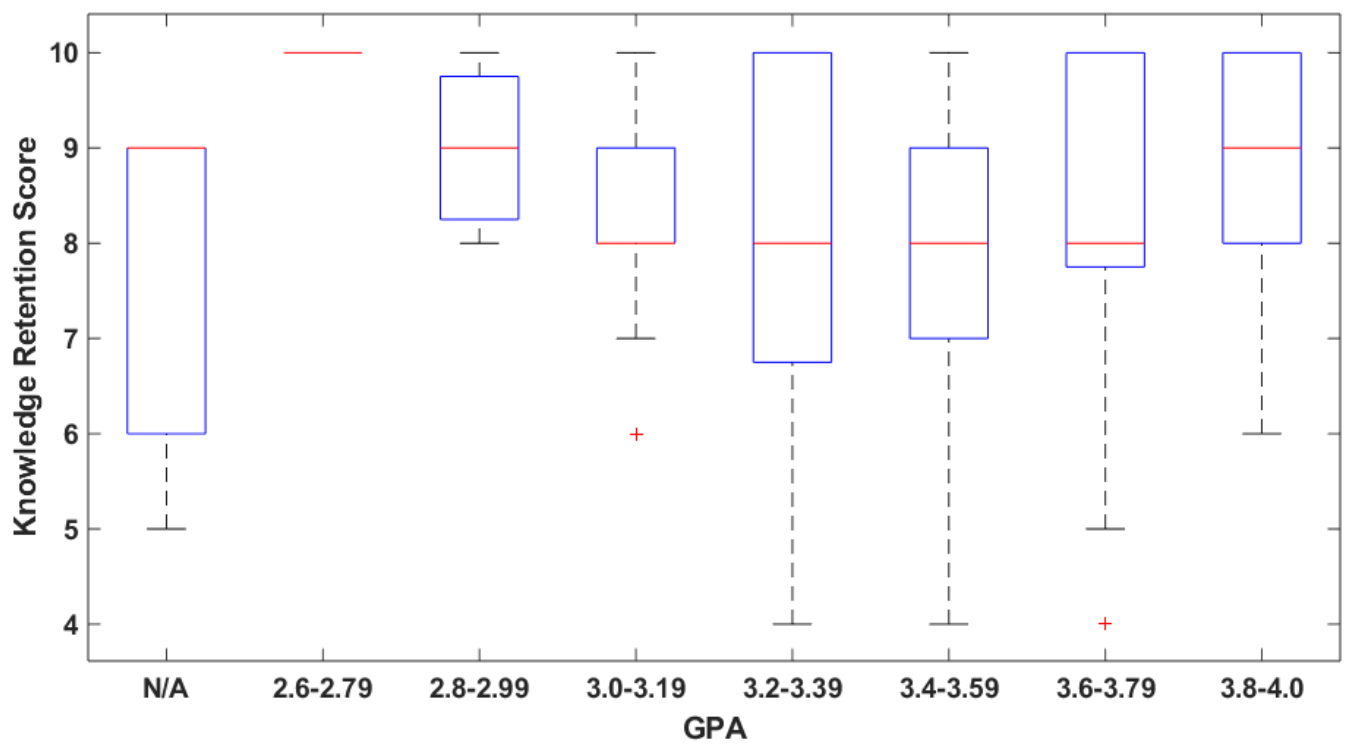

Figure 1. Box plot of the distribution of knowledge retention scores within each GPA range.

\section{Role of the Class Patent System on Student Learning Outcomes}

Box plots of the score distributions for students grouped according to their participation level in the class patent system are shown in figure 2. The average knowledge retention score and the $90 \%$ confidence intervals for each group is provided in table 2 . The mean score for students with participation level 1 or 2 lies outside the $90 \%$ confidence interval of the score for students with participation level 0 . This result is especially notable given that the knowledge retention scores were generally so high. Still, the difference in the sample means is just beyond the normally accepted level of statistical significance, $p=0.052$. A 2-factor model incorporating both participation level and GPA did not increase the statistical significance of these results, but 
further emphasized that the knowledge retention score has a much stronger correlation with participation level than with GPA. It is hoped that a repeated study with larger sample sizes and/or a more difficult set of knowledge retention questions which yields a larger spread in the retention scores may improve the statistical significance of this result.

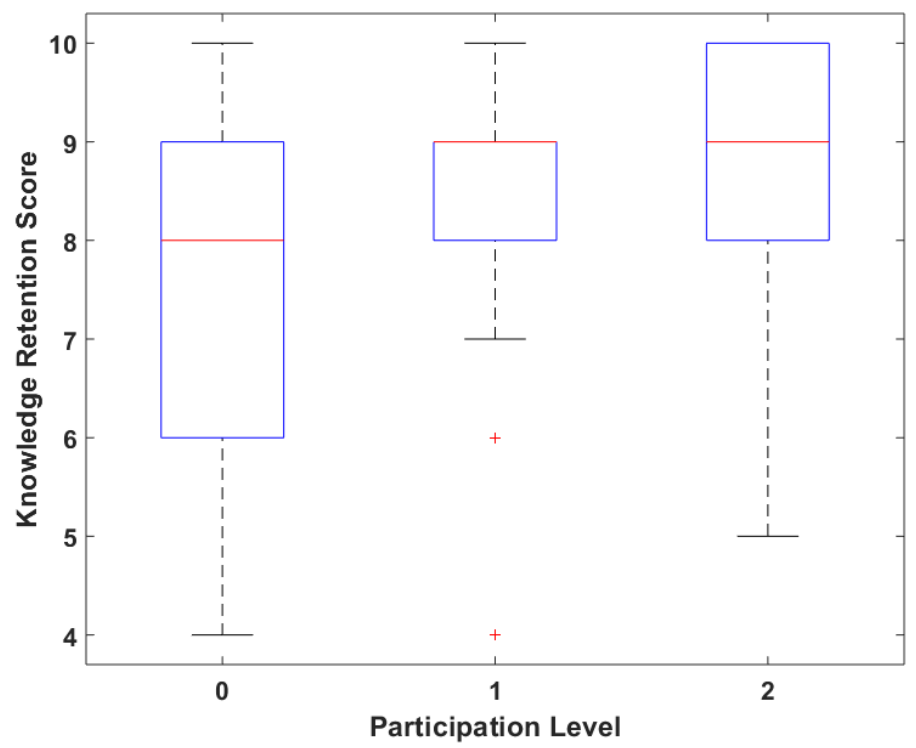

Figure 2. Box plot of the distribution of knowledge retention scores within each participation level.

Table 2. The knowledge retention scores for students with each participation level.

\begin{tabular}{|c|c|c|c|}
\cline { 3 - 4 } \multicolumn{2}{c|}{} & \multicolumn{2}{c|}{ Knowledge Retention Score } \\
\cline { 3 - 4 } \multicolumn{2}{c|}{} & mean & $\mathbf{9 0 \%}$ confidence interval \\
\hline \multirow{2}{*}{$\begin{array}{c}\text { Participation } \\
\text { Level }\end{array}$} & $\mathbf{0}$ & 7.72 & $7.15-8.28$ \\
\cline { 2 - 4 } & $\mathbf{1}$ & 8.43 & $8.05-8.80$ \\
\cline { 2 - 4 } & $\mathbf{2}$ & 8.50 & $8.21-8.79$ \\
\hline
\end{tabular}

\section{Role of the class patent system on student experience}

Students reported very favorable opinions of the class patent system. The vast majority of the students, $92 \%$, reported that the class patent system led to "some" or "a lot" of learning about intellectual property. The majority of students, $64 \%$, responded that the presence of the patent system led their team to develop project ideas more quickly. As with the real patent system, the class patent system thus fulfilled the purpose of encouraging rapid innovation. A similar proportion of the students, $61 \%$, stated that the patent system also led to a more competitive class environment. Nevertheless, when asked whether the class patent system led to a stressful classroom environment, 79\% said that it did only "very little" or "not at all". Only 2 of the 132 respondents said that the class patent system had a "somewhat negative" impact on the class environment and no one said the impact was "highly negative." Student perceptions of the effects of the class patent system are summarized in Figure 3. 


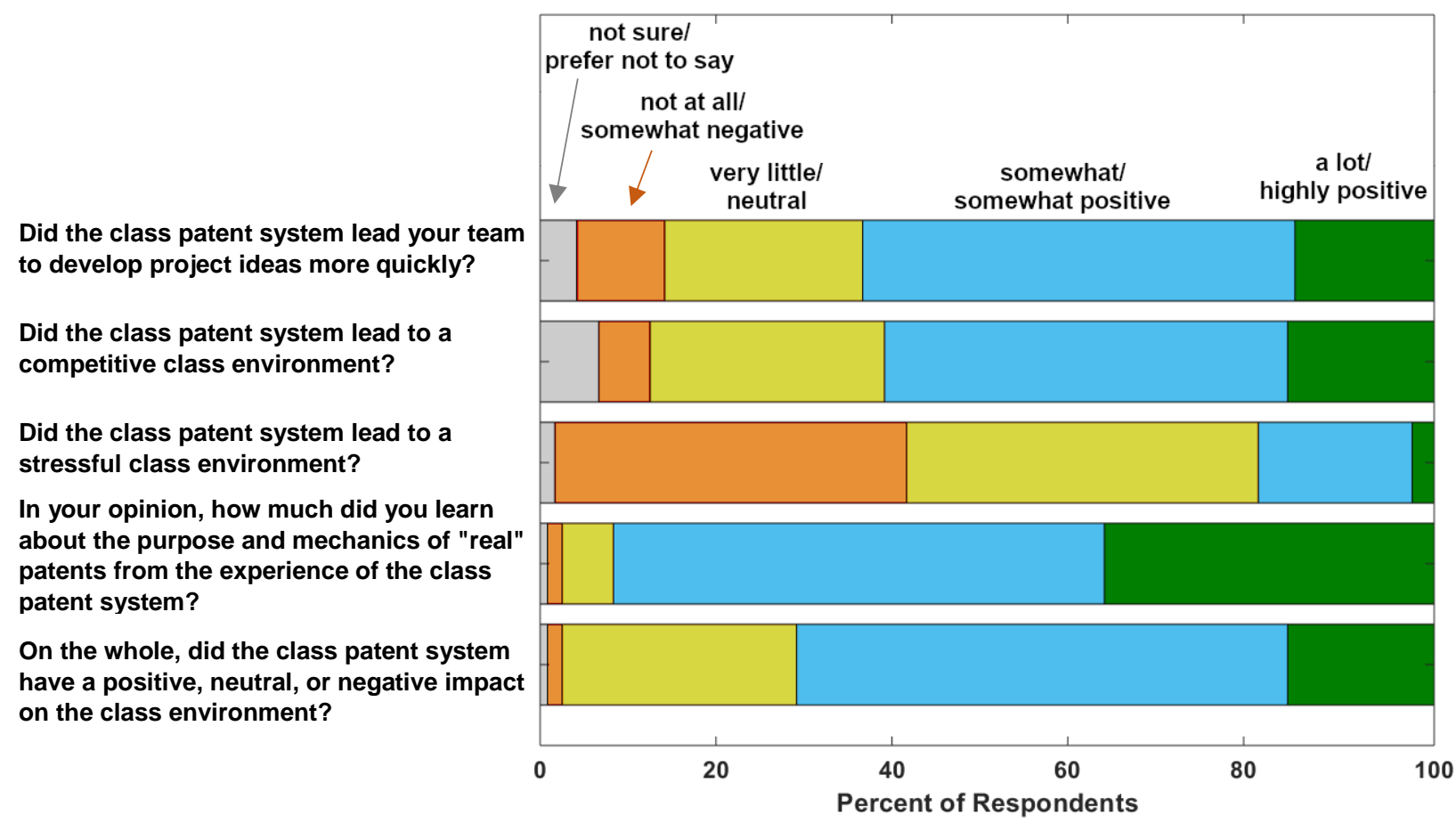

Figure 3. Responses to questions about the effects of the class patent system on class environment.

Responses are color coded as indicated at the top of the plot.

Near the end of the survey, students were presented a list of 20 terms or phrases and asked to select several that they felt described the class patent system. To balance the selections, each term or phrase in the list had its antonym present. The ordering of the terms in the list was shuffled each survey to prevent a selection bias towards items at the top of the list. The least commonly chosen terms, each selected by 2 or fewer students, were "boring", "discouraging", "unfair", "worthless", and "unimpactful." On the other hand, the five terms most commonly chosen were "interesting", "applicable to real life", "motivating", "useful", and "straightforward", with the first three of those terms being selected by an outright majority of the respondents.

\section{Conclusions and Recommendations}

The learning activity described in this paper was found to be an effective way to have students directly experience the purposes and mechanisms of patents. Implementing such a system in a class requires there to be a project that has: 1) significant student autonomy in making design decisions such that the students can generate meaningfully original ideas and 2) some degree of competition such that students may proactively choose to pursue a patent to gain a competitive advantage. While there is additional instructor effort required to supplement a design project with a class patent system, the data presented here suggests that it is effective in furthering intellectual property-related learning outcomes and leads students to seek new project ideas more quickly, all without increasing student stress. 


\section{References}

[1] M.E. Gorman, L.G. Richards, W.T. Scherer, and J.K. Kagiwada, "Teaching invention and design: multi-disciplinary learning modules," Journal of Engineering Education, vol. 84, pp. 175-185, 1995.

[2] C.A. Garris, Jr. and C.A. Garris, III, "The United States patent system and engineering education: an alliance for innovation," Technology \& Innovation, vol. 19, pp. 509-524, 2017.

[3] T. Ozkul, "Using patents as a tool for reinforcing constructivist learning environment in engineering education," International Journal of Education and Information Technologies, vol. 2, pp. 157-166, 2008.

[4] L. Liebenberg and E.H. Mathews, "Integrating innovation skills in an introductory engineering design-build course," International Journal of Technology and Design Education, vol. 22, pp. 93-113, 2012.

[5] A. Vairis and M. Petousis, "Intellectual property teaching as part of an engineering degree," Engineering Leaders Conference 2014, [http://dx.doi.org/10.5339/qproc.2015.elc2014.45].

[6] R. Soetendorp, "'Food for engineers': intellectual property education for innovators," Industry \& Higher Education, vol. 18, pp. 363-375, 2004.

[7] D.A. Kolb, Experiential Learning: Experience as the Source of Learning and Development, Upper Saddle River, New Jersey: Pearson Education, 2014.

[8] M. Buchmann and J. Schwille, "Education: the overcoming of experience," American Journal of Education, vol. 92, pp. 30-51, 1983.

[9] S.A. Ambrose, M.W. Bridges, M. DiPietro, M.C. Lovett, M.K. Norman, How Learning Works: Seven Research-Based Principles for Smart Teaching, San Francisco, California: Jossey-Bass, 2010. 


\section{Appendix A - Example Class Patent Application}

Below is an example patent application, based on an actual submission. The inventor's names are "blacked out" as would be done when the application is posted to the class Blackboard site.

Application Date: February 6, 2016

Assignee: Team $\mathrm{T}=\mathrm{MC}^{2}$

Inventors:

\section{Slit Based Focusing Sensor Enclosure}

This patent is for a system that uses a variable sized slit to control light exposed to a photoresistor. This would allow the photoresistor to detect which direction light is coming from, and gives it the ability to control the field of view of the sensor by adjusting the size of the slit.

\section{Claims:}

1) Any device that uses an enclosure around a light sensor with a resizable slit or aperture on the detection end to control light entry is covered by this patent. The size of the slit controls the angles that light can enter the box and shine directly on the photoresistor located within.

2) Any device using a method to control light entering said enclosure by varying the size of an aperture is covered by this patent. The aperture can be a circular camera type aperture, a slit which can be varied in size, or any other device which opens and closes in order to control light entry.

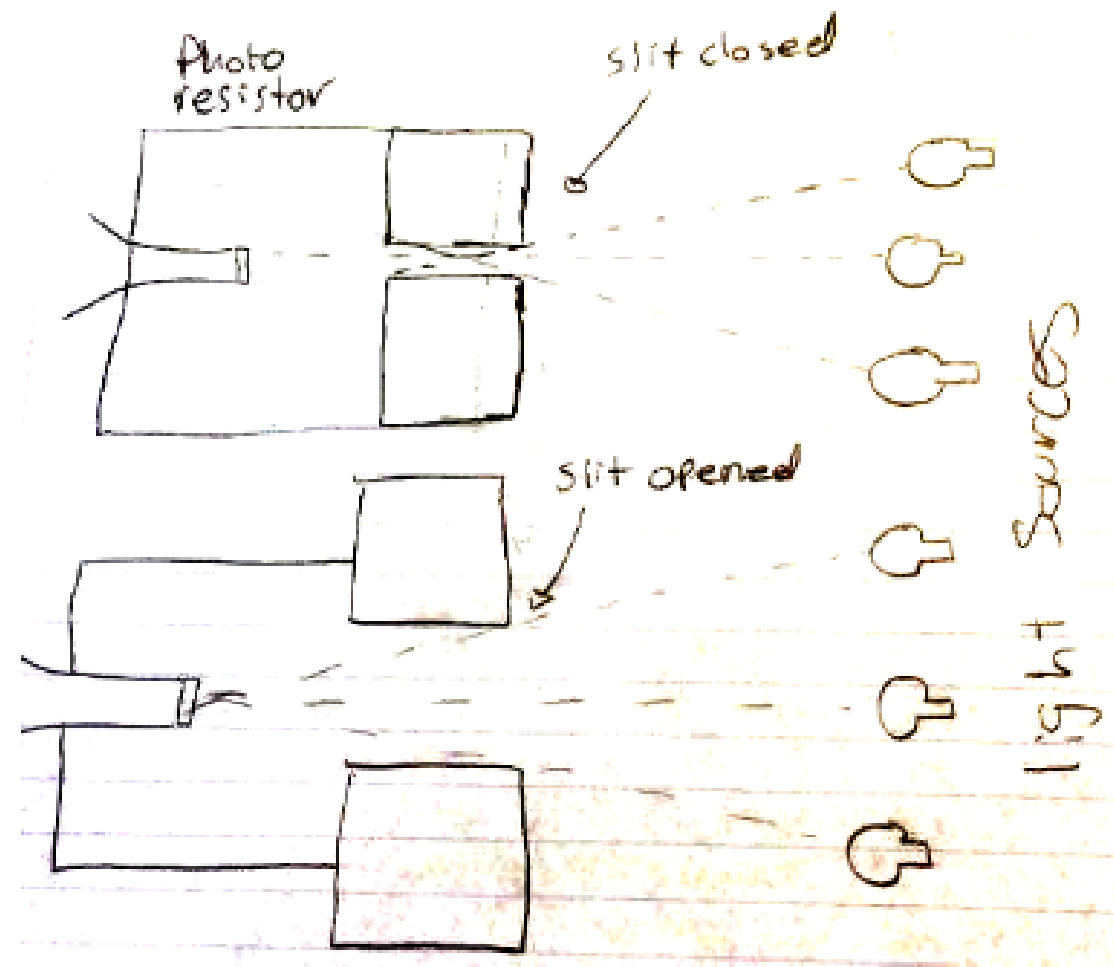

